\title{
Step and Distance Measurement From a Low-Cost Consumer-Based Hip and Wrist Activity Monitor: Protocol for a Validity and Reliability Assessment
}

\author{
Thomas Carlin ${ }^{1,2}$, MSc; Nicolas Vuillerme ${ }^{1,2,3}, \mathrm{PhD}$ \\ ${ }_{1}^{1}$ AGEIS, University Grenoble Alpes, Grenoble, France \\ ${ }^{2}$ LabCom Telecom4Health, University Grenoble Alpes \& Orange Labs, Grenoble, France \\ ${ }^{3}$ Institut Universitaire de France, Paris, France
}

\section{Corresponding Author:}

Nicolas Vuillerme, $\mathrm{PhD}$

AGEIS

University Grenoble Alpes

Faculty of Medicine

Grenoble,

France

Phone: 33476637104

Email: nicolas.vuillerme@univ-grenoble-alpes.fr

\section{Abstract}

Background: Self-tracking via wearable and mobile technologies is becoming an essential part of personal health management. At this point, however, little information is available to substantiate the validity and reliability of low-cost consumer-based hip and wrist activity monitors, with regard more specifically to the measurements of step counts and distance traveled while walking.

Objective: The aim of our study is to assess the validity and reliability of step and distance measurement from a low-cost consumer-based hip and wrist activity monitor specific in various walking conditions that are commonly encountered in daily life. Specifically, this study is designed to evaluate whether and to what extent validity and reliability could depend on the sensor placement on the human body and the walking task being performed.

Methods: Thirty healthy participants will be instructed to wear four PBN 2433 (Nakosite) activity monitors simultaneously, with one placed on each hip and each wrist. Participants will attend two experimental sessions separated by 1 week. During each experimental session, two separate studies will be performed. In study 1, participants will be instructed to complete a 2-minute walk test along a 30-meter indoor corridor under 3 walking speeds: very slow, slow, and usual speed. In study 2, participants will be required to complete the following 3 conditions performed at usual walking speed: walking on flat ground, upstairs, and downstairs. Activity monitor measured step count and distance values will be computed along with the actual step count (determined from video recordings) and distance (measured using a measuring tape) to determine validity and reliability for each activity monitor placement and each walking condition.

Results: Participant recruitment and data collection began in January 2020. As of June 2020, we enrolled 8 participants. Dissemination of study results in peer-reviewed journals is expected in spring 2021.

Conclusions: To the best of our knowledge, this is the first study that examines the validity and reliability of step and distance measurement during walking using the PBN 2433 (Nakosite) activity monitor. Results of this study will provide beneficial information on the effects of activity monitor placement, walking speed, and walking tasks on the validity and reliability of step and distance measurement. We believe such information is of utmost importance to general consumers, clinicians, and researchers.

International Registered Report Identifier (IRRID)： DERR1-10.2196/21262

(JMIR Res Protoc 2021;10(1):e21262) doi: $\underline{10.2196 / 21262}$

\section{KEYWORDS}

activity monitor; pedometer; measurement; validity; reliability; walking; step count; distance 


\section{Introduction}

Self-tracking via wearable and mobile technologies is becoming an essential part of personal health management $[1,2]$. In recent years, wearable devices such as those made by Fitbit (eg, One, Flex, Ultra) and ActiGraph (GT9X, GT3X) have been widely introduced into the consumer market as physical activity monitors. The relatively low cost, interface capabilities, ease of use, and wide commercial availability of these devices may ultimately change the way researchers and clinicians alike monitor their patients' physical activity $[3,4]$ by providing remote access to patient-generated data [5]. In particular, Fitbit [6-14] and ActiGraph [15-25] trackers have received considerable attention.

Depending on the type of activity monitor, companies recommend wearing them at the waist, wrist, pocket, hip, or bra. These wearables devices contain different tools for measurement such as piezoelectric pedometers, single triaxial accelerometers, or inertial measurement unit that combine accelerometers, gyroscopes, and sometimes magnetometers. Using proprietary algorithms, data from measures collected along with information input by the user can estimate steps, distance, physical activity, kilocalories, and sleep [4,5,25,26]. Among these outputs, step and distance measurements while walking remain the most popular and translatable outputs in use today [4,25,27-29].

At this point, it is important to recall that valid and reliable step count and distance estimates are vital output metrics and constitute crucial selection criteria for use in clinical practice [28]. However, little information is available to substantiate the validity and reliability of step and distance measurement from consumer-based hip and wrist activity monitors [26,30,31]. More specifically, despite the increasing number of published works on the evaluation of the most well-known activity monitors [17,25,27,32,33], only a few addressed low-cost activity monitors. For instance, the GT3X (ActiGraph LLC), one of the most well-known and studied accelerometer in research and clinical setting [6-14], costs around $€ 225$ (US $\$ 250$ ) for one device [34] plus the price of the software and accessories. Fitbit activity trackers also have been the subject of many studies [15-25]; for example, the Charge (Fitbit Inc) costs around $€ 150$ (US \$170) [35]. This observation is all the more relevant as the selling price is a main barrier to purchase [36]. Indeed, numerous activity monitors available on the market are rather expensive and beyond the financial means of a significant segment of society.

Within this context, the aim of our study is to assess the validity and reliability of step and distance measurement from a low-cost consumer-based hip and wrist activity monitor specific to various walking conditions commonly encountered in daily life. This study is designed to evaluate whether and to what extent validity and reliability of step and distance measurement from a consumer-based hip and wrist activity monitor could depend on the sensor placement on the human body and the walking task being performed. Human locomotion in daily life involves walking at non-self-selected speeds, walking upstairs, walking downstairs, turning... in other words, not just straight line walking on flat ground at a comfortable speed. While reliability and validity of activity monitors for walking on flat ground is quite well documented in the growing literature on the subject [20,23,26,37-54], ascending and descending stairs has received less attention [20,23,44-48,50,51,53,55].

\section{Methods}

\section{Participants}

Young healthy adults aged 18 to 40 years will voluntarily participate to this work. Participants will be recruited in the Grenoble area (France) through open recruitment and direct invitation. From previous similar studies, we have identified that a minimum of 30 participants will be necessary to demonstrate significant differences between the experimental settings $[38,47,56,57]$. Participants cannot have any history of injury, surgery, or pathology to lower extremities that affects their gait.

The following participant demographic and anthropometric data will be collected: gender, age, body height, body weight, foot length, dominant leg, dominant arm, leg length, arm length, and physical activity level.

Each participant will sign a written informed consent prior to their participation in compliance with the Declaration of Helsinki. This study was approved by the local ethics committee (CER Grenoble Alpes, Avis 2019-04-09-4).

\section{Materials}

\section{Activity Monitors}

The PBN 2433 (Nakosite USA Ltd) activity monitor has been selected according to previous recommendations that an activity monitor should cost less than $€ 150$ (US \$185), require no monthly costs for a subscription, provide real-time feedback to the user, and have no chest strap for heart rate measurements [58,59].

The PBN 2433 is a small, inexpensive activity monitor (dimensions: $12 \mathrm{~mm} \times 8 \mathrm{~mm} \times 4 \mathrm{~mm}$; weight: $31.2 \mathrm{~g}$; $€ 15$ [US \$20]) worn on a wrist band or clipped on the hip. The PBN 2433 tracks step count (total steps per day), calories burned (kcal/day), distance traveled ( $\mathrm{km} /$ day), and exercise time (h/day). A multiple LCD screen displays direct feedback on outputs. No Bluetooth connection, supplementary app, or mobile or smartphone are needed. It sets up with weight $(\mathrm{kg})$ and stride length $(\mathrm{cm})$. Weight will be obtained by asking participant about their approximative weight. For stride length measurement, participant will be asked to walk 10 steps and the distance traveled will be divided by 10 to obtain an average stride length as is recommended by the manufacturer.

During all experiments, participants will be asked to wear four PBN 2433 activity monitors simultaneously in these locations on their body:

- Fitted on the right hip, positioned over the right anterior iliac spine via the manufacturer-provided silicone clip

- $\quad$ Fitted on the left hip, positioned over the left anterior iliac spine via the manufacturer-provided silicone clip 
- $\quad$ Fitted to the right wrist using the manufacturer-provided wristband and positioned on the dorsal aspect of the wrist just proximal to the radial and ulnar processes

- Fitted to the left wrist using the manufacturer-provided wristband and positioned on the dorsal aspect of the wrist just proximal to the radial and ulnar processes

\section{Video Processing}

Participants will also be videorecorded with an embedded camera (HERO4, GoPro Inc) fixed on the chest thanks to the dedicated harness. The camera lens will be oriented toward the ground in order to capture all steps taken by the participant. In other words, as previously done by others [19,22,23,30,38,43,45,56,58,60-64], we will use the video-based step count as the gold standard for actual step count. Video-based step counting will be independently conducted by two observers, with a third observer repeating the count in case of discrepancy between obtained step counts $[27,28,65,66]$.

\section{Experimental Procedure}

Participants will attend two similar experimental sessions in an indoor environment separated by 1 week. During each experimental session, two different experiments will be conducted.

In experiment 1 , as was previously proposed in published studies designed to evaluate the validity of activity monitors for measuring step counts and distance traveled while walking [18,20,24,54], participants will be required to complete a standard 2-minute walk test during which they will be videotaped. This walking task will be performed in an enclosed, wide, long, flat, 30-m corridor with the instruction to walk back and forth on the course all throughout the 2-minute period. This walking task will be performed under 3 walking speed [67]: (1) very slow walking speed, with the instruction "Walk very slowly"; (2) slow walking speed, with the instruction "Walk a little faster, but slower than normal"; and (3) usual walking speed, with the instruction "Walk at your normal, preferred speed."

In experiment 2, participants will be videotaped during the walking task performed at usual walking speed under 3 conditions $[68,69]$ : walking on flat ground, walking upstairs, and walking downstairs.

During the walking on flat ground condition, participants will complete a standard 2-minute walk test as proposed in experiment 1 . During the walking upstairs condition, participants will be asked to ascend flights of stairs located inside a building stairwell for 2 minutes. During the walking downstairs condition, participants will be asked to descend flights of stairs located inside a building stairwell for 2 minutes. At this point, it is important to mention that handrails do represent important safety features to assist users to maintain their balance and prevent falls on stairs. However, for methodological reasons, participants will not be permitted to use handrails on stairs in the walking upstairs and walking downstairs experimental conditions.

During each experimental session and for each experiment, the order of the 3 experimental conditions will be randomized over participants to reduce potential carryover effects. Only one 2-minute walking trial per condition will be performed. Before to the formal walking trial, participants will complete a practice trial to familiarize themselves with the walking task. A 2-minute rest period will be given between each walking trial in order to record the step and distance counts from each activity monitor. During this period, participants will be instructed to stand still. The number of steps and walking distance measured by each activity monitor will be noted from the tracker display before and immediately after the completion of each trial.

\section{Statistical Analysis}

Descriptive statistics and their corresponding 95\% confidence intervals will be determined for all dependent variables. Step count and walking distance errors from each activity monitor will further be calculated as follows:

- $\quad$ Step count error $=[($ steps measured - actual steps $) /$ actual steps] x 100\%

- Distance error $=[($ distance measured - actual distance $)]$ actual distance] $\times 100 \%$

where:

- $\quad$ Steps counted and distance measured are the value of steps and distance provided by the activity monitor

- Actual steps is the number of steps manually counted from video

- Actual distance is the distance measured using a measuring tape

An error score of zero indicates no difference; a positive error score represents an overestimation of the step and distance counts; a negative error score represents an underestimation.

Validity will be determined by comparing the activity monitor outputs (step and walking distance) with the criterion measures (ie, step count determined from video recordings and distance measured using a measuring tape), using mean differences, mean absolute percentage errors (MAPE), and intraclass correlation coefficients (ICC). According to Feito et al [70,71], a MAPE exceeding 5\% can be considered as a practically relevant difference. Repeated-measures analysis of variance (ANOVA) will be used to determine whether a significant difference exists between validity of activity monitor placements and walking conditions. In cases when ANOVA shows a significant difference, post hoc analysis will be performed via Bonferroni tests or, when variances is not assumed to be equal, via Games-Howell tests.

The correlation and level of agreement of the steps and distances estimated by the activity monitor to the criterion measures will be further assessed by calculating a Spearman correlation coefficient or Pearson correlation coefficient $(r)$ and ICC, respectively. The parametrical or nonparametrical correlation formula is selected based on the linearity of the relationship between the two measured variables. A correlation coefficient value from .00 to .20 is considered poor, .20 to .40 fair, .40 to .60 moderate, .60 to .80 substantial, and .80 to 1.00 almost perfect [72]. An ICC value from .00 to .40 is considered poor, .40 to .59 fair, .60 to .74 good, and .75 to 1.00 excellent [73]. Bland-Altman plots will further be constructed to visually assess 
agreement of activity monitor estimates with the criterion measures [74].

Between-day reliability will be determined by calculating ICC between results obtained during session 1 and session 2 . We will also compute the mean differences, standard error of measurements, and the MAPE between both experimental sessions. Significant differences between session 1 and session 2 will be determined by paired-sample $t$ test or its nonparametric equivalent, the Wilcoxon signed-rank test. A Bland-Altman plot will be constructed to analyze the agreement between the two assessments.

Statistical significance will be set a priori at $P<.05$. All statistical calculations will be completed using the R software environment version 3.1.0 (R Foundation for Statistical Computing).

\section{Results}

Participant recruitment and data collection began in January 2020. As of June 2020, we enrolled 8 participants. Dissemination of study results in peer-reviewed journals is expected in spring 2021.

\section{Discussion}

Physical activity is now widely recognized as crucial for health status maintenance [75-78], whereas physical inactivity has been identified as one of the most important factors in the rise of noncommunicable diseases [78,79]. For these reasons, regular daily physical activity is fully recommended [41,80,81]. It is known that real-time monitoring of physical activity can lead to a perceptible improvement of the physical activity level $[2,82-84]$. Various activity monitors are available on the market for this purpose. Most of them are designed to measure steps and distance traveled while walking $[4,5,26,27]$. Although their beneficial effect on health is now well documented [2,82-84], little information is available to substantiate the validity and reliability of step and distance measurement, especially from low-cost consumer-based hip and wrist activity monitors.

To the best of our knowledge, this is the first study that examines the validity and reliability of step and distance measurement during walking conditions using the PBN 2433 activity monitor. To achieve this goal, young healthy participants will be asked to wear four PBN 2433 activity monitors simultaneously, placed on each hip and each wrist. Participants will be also instructed to perform various walking conditions that are commonly encountered in daily life during two experimental sessions.

On the whole, considering the existing literature on the topic, we hypothesize that the validity and reliability of step count and distance output from the PBN 2433 activity monitors will depend on the following factors:

- Sensor placement locations on the user's body $[21,38,46,51,85,86]$

- Walking speed [38,55,87-91]

- $\quad$ Walking tasks being performed [23,46,50,55]

Taken together, these will provide beneficial information on the effects of activity monitor placement, walking speed, and walking tasks on validity and reliability of step and distance measurement. We believe that such information is of utmost importance to general consumers, clinicians, and researchers.

\section{Acknowledgments}

This work was supported by the French National Research Agency in the framework of the Investissements d'avenir program (ANR-10-AIRT-05 and ANR-15-IDEX-02). The sponsors had no involvement in the study or approval of the manuscript for publication. This work forms part of a broader translational and interdisciplinary project, GaitAlps (NV).

\section{Conflicts of Interest}

None declared.

\section{References}

1. Kumahara H, Ishii K, Tanaka H. Physical activity monitoring for health management: practical techniques and methodological issues. Int J Sport Health Sci 2006;4:380-393. [doi: 10.5432/ijshs.4.380]

2. Bravata DM, Smith-Spangler C, Sundaram V, Gienger AL, Lin N, Lewis R, et al. Using pedometers to increase physical activity and improve health: a systematic review. JAMA 2007 Nov 21;298(19):2296-2304. [doi: 10.1001/jama.298.19.2296] [Medline: 18029834]

3. Bassett DR, John D. Use of pedometers and accelerometers in clinical populations: validity and reliability issues. Physical Therapy Rev 2013 Jul 19;15(3):135-142. [doi: 10.1179/1743288x10y.0000000004]

4. Tudor-Locke CE, Myers AM. Methodological considerations for researchers and practitioners using pedometers to measure physical (ambulatory) activity. Res Q Exerc Sport 2001 Mar;72(1):1-12. [doi: 10.1080/02701367.2001.10608926] [Medline: 11253314]

5. Tudor-Locke C, Lutes L. Why do pedometers work? A reflection upon the factors related to successfully increasing physical activity. Sports Med 2009;39(12):981-993. [doi: 10.2165/11319600-000000000-00000] [Medline: 19902981]

6. Chomistek A, Yuan C, Matthews C, Troiano R, Bowles H, Rood J, et al. Physical activity assessment with the ActiGraph GT3X and doubly labeled water. Med Sci Sports Exerc 2017 Sep;49(9):1935-1944 [FREE Full text] [doi: 10.1249/MSS.0000000000001299] [Medline: 28419028]

7. Hänggi JM, Phillips LR, Rowlands AV. Validation of the GT3X ActiGraph in children and comparison with the GT1M ActiGraph. J Sci Med Sport 2013 Jan;16(1):40-44. [doi: 10.1016/j.jsams.2012.05.012] [Medline: 22749938] 
8. Kim Y, Barry VW, Kang M. Validation of the ActiGraph GT3X and activPAL accelerometers for the assessment of sedentary behavior. Measurement Physical Educ Exercise Sci 2015 Aug 19;19(3):125-137. [doi: $\underline{10.1080 / 1091367 x .2015 .1054390]}$

9. Romanzini M, Petroski EL, Ohara D, Dourado AC, Reichert FF. Calibration of ActiGraph GT3X, Actical and RT3 accelerometers in adolescents. Eur J Sport Sci 2014;14(1):91-99. [doi: 10.1080/17461391.2012.732614] [Medline: 24533499]

10. Santos-Lozano A, Santín-Medeiros F, Cardon G, Torres-Luque G, Bailón R, Bergmeir C, et al. Actigraph GT3X: validation and determination of physical activity intensity cut points. Int J Sports Med 2013 Nov;34(11):975-982. [doi: 10.1055/s-0033-1337945] [Medline: 23700330]

11. Santos-Lozano A, Torres-Luque G, Marín PJ, Ruiz J, Lucia A, Garatachea N. Intermonitor variability of GT3X accelerometer. Int J Sports Med 2012 Dec;33(12):994-999. [doi: 10.1055/s-0032-1312580] [Medline: 22791617]

12. Santos-Lozano A, Marín P, Torres-Luque G, Ruiz JR, Lucía A, Garatachea N. Technical variability of the GT3X accelerometer. Med Eng Phys 2012 Jul;34(6):787-790. [doi: 10.1016/j.medengphy.2012.02.005] [Medline: 22417978]

13. Wanner M, Martin BW, Meier F, Probst-Hensch N, Kriemler S. Effects of filter choice in GT3X accelerometer assessments of free-living activity. Med Sci Sports Exerc 2013 Jan;45(1):170-177. [doi: 10.1249/MSS.0b013e31826c2cf1] [Medline: 22895373]

14. García-Massó X, Serra-Añó P, García-Raffi LM, Sánchez-Pérez EA, López-Pascual J, Gonzalez LM. Validation of the use of Actigraph GT3X accelerometers to estimate energy expenditure in full time manual wheelchair users with spinal cord injury. Spinal Cord 2013 Dec;51(12):898-903. [doi: 10.1038/sc.2013.85] [Medline: 23999111]

15. Haghayegh S, Khoshnevis S, Smolensky MH, Diller KR, Castriotta RJ. Accuracy of wristband Fitbit models in assessing sleep: systematic review and meta-analysis. J Med Internet Res 2019 Nov 28;21(11):e16273 [FREE Full text] [doi: 10.2196/16273] [Medline: 31778122]

16. Gorny AW, Liew SJ, Tan CS, Müller-Riemenschneider F. Fitbit Charge HR wireless heart rate monitor: validation study conducted under free-living conditions. JMIR Mhealth Uhealth 2017 Oct 20;5(10):e157 [FREE Full text] [doi: 10.2196/mhealth.8233] [Medline: 29055881]

17. Feehan LM, Geldman J, Sayre EC, Park C, Ezzat AM, Yoo JY, et al. Accuracy of Fitbit devices: systematic review and narrative syntheses of quantitative data. JMIR Mhealth Uhealth 2018 Aug 09;6(8):e10527 [FREE Full text] [doi: 10.2196/10527] [Medline: $\underline{30093371]}$

18. Haegele J, Brian A, Wolf D. Accuracy of the Fitbit Zip for measuring steps for adolescents with visual impairments. Adapt Phys Activ Q 2017 Apr;34(2):195-200. [doi: 10.1123/apaq.2016-0055] [Medline: 28556761]

19. Diaz KM, Krupka DJ, Chang MJ, Peacock J, Ma Y, Goldsmith J, et al. Fitbit: An accurate and reliable device for wireless physical activity tracking. Int J Cardiol 2015 Apr 15;185:138-140. [doi: 10.1016/j.ijcard.2015.03.038] [Medline: 25795203]

20. Chandrasekar A, Hensor EM, Mackie SL, Backhouse MR, Harris E. Preliminary concurrent validity of the Fitbit-Zip and ActiGraph activity monitors for measuring steps in people with polymyalgia rheumatica. Gait Posture 2018 Mar;61:339-345. [doi: 10.1016/j.gaitpost.2018.01.035] [Medline: 29427859]

21. Kooiman TJM, Dontje ML, Sprenger SR, Krijnen WP, van der Schans CP, de Groot M. Reliability and validity of ten consumer activity trackers. BMC Sports Sci Med Rehabil 2015 Oct; 7:24 [FREE Full text] [doi: 10.1186/s13102-015-0018-5] [Medline: 26464801]

22. Wong CK, Mentis HM, Kuber R. The bit doesn't fit: evaluation of a commercial activity-tracker at slower walking speeds. Gait Posture 2018 Jan;59:177-181. [doi: 10.1016/j.gaitpost.2017.10.010]

23. Huang Y, Xu J, Yu B, Shull PB. Validity of FitBit, Jawbone UP, Nike+ and other wearable devices for level and stair walking. Gait Posture 2016 Jul;48:36-41. [doi: 10.1016/j.gaitpost.2016.04.025]

24. Paul SS, Tiedemann A, Hassett LM, Ramsay E, Kirkham C, Chagpar S, et al. Validity of the activity tracker for measuring steps in community-dwelling older adults. BMJ Open Sport Exerc Med 2015 Jul;1(1):e000013 [FREE Full text] [doi: 10.1136/bmjsem-2015-000013] [Medline: 27900119]

25. Evenson KR, Goto MM, Furberg RD. Systematic review of the validity and reliability of consumer-wearable activity trackers. Int J Behav Nutr Phys Act 2015;12(1):159 [FREE Full text] [doi: 10.1186/s 12966-015-0314-1] [Medline: 26684758]

26. An H, Jones GC, Kang S, Welk GJ, Lee J. How valid are wearable physical activity trackers for measuring steps? Eur J Sport Sci 2017 Apr;17(3):360-368. [doi: 10.1080/17461391.2016.1255261] [Medline: 27912681]

27. Bassett DR, Toth LP, LaMunion SR, Crouter SE. Step counting: a review of measurement considerations and health-related applications. Sports Med 2017 Jul;47(7):1303-1315 [FREE Full text] [doi: 10.1007/s40279-016-0663-1] [Medline: 28005190]

28. Saint-Maurice PF, Troiano RP, Bassett DR, Graubard BI, Carlson SA, Shiroma EJ, et al. Association of daily step count and step intensity with mortality among US adults. JAMA 2020 Mar 24;323(12):1151-1160 [FREE Full text] [doi: 10.1001/jama.2020.1382] [Medline: $\underline{\text { 32207799] }}$

29. O'Driscoll R, Turicchi J, Beaulieu K, Scott S, Matu J, Deighton K, et al. How well do activity monitors estimate energy expenditure? A systematic review and meta-analysis of the validity of current technologies. Br J Sports Med 2020 Mar;54(6):332-340. [doi: 10.1136/bjsports-2018-099643] [Medline: 30194221]

30. Alinia P, Cain C, Fallahzadeh R, Shahrokni A, Cook D, Ghasemzadeh H. How accurate is your activity tracker? A comparative study of step counts in low-intensity physical activities. JMIR Mhealth Uhealth 2017 Aug 11;5(8):e106 [FREE Full text] [doi: 10.2196/mhealth.6321] [Medline: 28801304] 
31. Thorup CB, Andreasen JJ, Sørensen EE, Grønkjær M, Dinesen BI, Hansen J. Accuracy of a step counter during treadmill and daily life walking by healthy adults and patients with cardiac disease. BMJ Open 2017 Mar 31;7(3):e011742. [doi: 10.1136/bmjopen-2016-011742]

32. Corder K, Brage S, Ekelund U. Accelerometers and pedometers: methodology and clinical application. Curr Opin Clin Nutr Metab Care 2007 Sep;10(5):597-603. [doi: 10.1097/MCO.0b013e328285d883] [Medline: 17693743]

33. Kenyon A, McEvoy M, Sprod J, Maher C. Validity of pedometers in people with physical disabilities: a systematic review. Arch Phys Med Rehabil 2013 Jun;94(6):1161-1170. [doi: 10.1016/j.apmr.2012.11.030] [Medline: 23201318]

34. McMinn D, Acharya R, Rowe D, Gray S, Allan J. Measuring activity energy expenditure: accuracy of the GT3X+ and Actiheart monitors. Int J Exerc Sci 2013;6(3):5 [FREE Full text]

35. Ricchio K, Lyter-Antonneau PM. Reliability of fitness trackers at different prices for measuring steps and heart rate: a pilot study. Centr Eur J Sport Sci Med 2018;24:57-64. [doi: 10.18276/cej.2018.4-06]

36. Gualtieri L, Rosenbluth S, Phillips J. Can a free wearable activity tracker change behavior? The impact of trackers on adults in a physician-led wellness group. JMIR Res Protoc 2016 Nov 30;5(4):e237 [FREE Full text] [doi: 10.2196/resprot.6534] [Medline: 27903490]

37. Fortune E, Lugade V, Morrow M, Kaufman K. Validity of using tri-axial accelerometers to measure human movement part II: step counts at a wide range of gait velocities. Med Eng Phys 2014 Jun;36(6):659-669 [FREE Full text] [doi: 10.1016/j.medengphy.2014.02.006] [Medline: 24656871]

38. Ehrler F, Weber C, Lovis C. Influence of pedometer position on pedometer accuracy at various walking speeds: a comparative study. J Med Internet Res 2016 Oct 06;18(10):e268 [FREE Full text] [doi: 10.2196/jmir.5916] [Medline: 27713114]

39. Beltrán-Carrillo VJ, Jiménez-Loaisa A, Alarcón-López M, Elvira JLL. Validity of the "Samsung Health" application to measure steps: a study with two different samsung smartphones. J Sports Sci 2019 Apr;37(7):788-794. [doi: 10.1080/02640414.2018.1527199] [Medline: 30332917]

40. Dowd KP, Harrington DM, Donnelly AE. Criterion and concurrent validity of the activPAL ${ }^{\mathrm{TM}}$ professional physical activity monitor in adolescent females. PLoS One 2012;7(10):e47633 [FREE Full text] [doi: 10.1371/journal.pone.0047633] [Medline: 23094069]

41. Powell KE, Paluch AE, Blair SN. Physical activity for health: What kind? How much? How intense? On top of what? Annu Rev Public Health 2011;32:349-365. [doi: 10.1146/annurev-publhealth-031210-101151] [Medline: 21128761]

42. Hergenroeder AL, Barone Gibbs B, Kotlarczyk MP, Perera S, Kowalsky RJ, Brach JS. Accuracy and acceptability of commercial-grade physical activity monitors in older adults. J Aging Phys Act 2019 Apr 01;27(2):222-229 [FREE Full text] [doi: 10.1123/japa.2018-0036] [Medline: 30117355]

43. Simpson L, Eng J, Klassen T, Lim S, Louie D, Parappilly B, et al. Capturing step counts at slow walking speeds in older adults: comparison of ankle and waist placement of measuring device. J Rehabil Med 2015 Oct 05;47(9):830-835 [FREE Full text] [doi: 10.2340/16501977-1993] [Medline: 26181670]

44. Leicht AS, Crowther RG. Influence of non-level walking on pedometer accuracy. J Sci Med Sport 2009 May;12(3):361-365. [doi: 10.1016/j.jsams.2008.01.007] [Medline: 18356103]

45. O'Connell S, ÓLaighin G, Kelly L, Murphy E, Beirne S, Burke N, et al. These shoes are made for walking: sensitivity performance evaluation of commercial activity monitors under the expected conditions and circumstances required to achieve the international daily step goal of 10,000 steps. PLoS One 2016;11(5):e0154956 [FREE Full text] [doi: 10.1371/journal.pone.0154956] [Medline: 27167121]

46. Horvath S, Taylor DG, Marsh JP, Kriellaars DJ. The effect of pedometer position and normal gait asymmetry on step count accuracy. Appl Physiol Nutr Metab 2007 Jun;32(3):409-415. [doi: 10.1139/H07-001] [Medline: 17510675]

47. Chen M, Kuo C, Pellegrini C, Hsu M. Accuracy of wristband activity monitors during ambulation and activities. Med Sci Sports Exerc 2016 Oct;48(10):1942-1949. [doi: 10.1249/MSS.0000000000000984] [Medline: 27183123]

48. Magistro D, Brustio PR, Ivaldi M, Esliger DW, Zecca M, Rainoldi A, et al. Validation of the ADAMO Care Watch for step counting in older adults. PLoS One 2018;13(2):e0190753 [FREE Full text] [doi: 10.1371/journal.pone.0190753] [Medline: 29425196]

49. Martin JB, Krč KM, Mitchell EA, Eng JJ, Noble JW. Pedometer accuracy in slow walking older adults. Int J Ther Rehabil 2012 Jul 03;19(7):387-393 [FREE Full text] [doi: 10.12968/ijtr.2012.19.7.387] [Medline: 24795762]

50. Hazell TJ, Ellery CV, Cohen TR, Vanstone CA, Rodd CJ, Weiler HA. Assessment of pedometer accuracy in capturing habitual types of physical activities in overweight and obese children. Pediatr Res 2016 Nov;80(5):686-692. [doi: 10.1038/pr.2016.133] [Medline: 27486704]

51. Battenberg AK, Donohoe S, Robertson N, Schmalzried TP. The accuracy of personal activity monitoring devices. Sem Arthroplasty 2017 Jun;28(2):71-75. [doi: 10.1053/j.sart.2017.07.006]

52. Xie J, Wen D, Liang L, Jia Y, Gao L, Lei J. Evaluating the validity of current mainstream wearable devices in fitness tracking under various physical activities: comparative study. JMIR Mhealth Uhealth 2018 Apr 12;6(4):e94 [FREE Full text] [doi: 10.2196/mhealth.9754] [Medline: 29650506]

53. Kaewkannate K, Kim S. A comparison of wearable fitness devices. BMC Public Health 2016 Dec 24;16:433 [FREE Full text] [doi: 10.1186/s12889-016-3059-0] [Medline: 27220855] 
54. Fulk GD, Combs SA, Danks KA, Nirider CD, Raja B, Reisman DS. Accuracy of 2 activity monitors in detecting steps in people with stroke and traumatic brain injury. Phys Ther 2014 Feb;94(2):222-229 [FREE Full text] [doi: 10.2522/ptj.20120525] [Medline: 24052577]

55. Steeves J, Tyo B, Connolly C, Gregory D, Stark N, Bassett D. Validity and reliability of the Omron HJ-303 tri-axial accelerometer-based pedometer. J Phys Act Health 2011 Sep;8(7):1014-1020. [doi: 10.1123/jpah.8.7.1014] [Medline: 21885893]

56. O'Connell S, ÓLaighin G, Quinlan LR. When a step is not a step! Specificity analysis of five physical activity monitors. PLoS One 2017;12(1):e0169616 [FREE Full text] [doi: 10.1371/journal.pone.0169616] [Medline: 28085918]

57. Fokkema T, Kooiman T, Krijnen W, Van der Schans CP, De Groot M. Reliability and validity of ten consumer activity trackers depend on walking speed. Med Sci Sports Exerc 2017 Apr;49(4):793-800. [doi: 10.1249/MSS.0000000000001146] [Medline: 28319983]

58. Ummels D, Beekman E, Theunissen K, Braun S, Beurskens AJ. Counting steps in activities of daily living in people with a chronic disease using nine commercially available fitness trackers: cross-sectional validity study. JMIR Mhealth Uhealth 2018 Apr 02;6(4):e70 [FREE Full text] [doi: 10.2196/mhealth.8524] [Medline: 29610110]

59. Beekman E, Braun SM, Ummels D, van Vijven K, Moser A, Beurskens AJ. Validity, reliability and feasibility of commercially available activity trackers in physical therapy for people with a chronic disease: a study protocol of a mixed methods research. Pilot Feasibility Stud 2017;3:64 [FREE Full text] [doi: 10.1186/s40814-017-0200-5] [Medline: 29204293]

60. Klassen TD, Simpson LA, Lim SB, Louie DR, Parappilly B, Sakakibara BM, et al. "Stepping up" activity poststroke: ankle-positioned accelerometer can accurately record steps during slow walking. Phys Ther 2016 Mar;96(3):355-360 [FREE Full text] [doi: 10.2522/ptj.20140611] [Medline: 26251478]

61. Lauritzen J, Muñoz A, Luis Sevillano J, Civit A. The usefulness of activity trackers in elderly with reduced mobility: a case study. Stud Health Technol Inform 2013;192:759-762. [Medline: 23920659]

62. Toth LP, Park S, Springer CM, Feyerabend MD, Steeves JA, Bassett DR. Video-recorded validation of wearable step counters under free-living conditions. Med Sci Sports Exerc 2018 Jun;50(6):1315-1322. [doi: 10.1249/MSS.0000000000001569] [Medline: 29381649]

63. Tophøj KH, Petersen MG, Sæbye C, Baad-Hansen T, Wagner S. Validity and reliability evaluation of four commercial activity trackers' step counting performance. Telemed J E Health 2018 Sep;24(9):669-677. [doi: 10.1089/tmj.2017.0264] [Medline: 29303680]

64. McCullagh R, Dillon C, O'Connell AM, Horgan NF, Timmons S. Step-count accuracy of 3 motion sensors for older and frail medical inpatients. Arch Phys Med Rehabil 2017 Feb;98(2):295-302. [doi: 10.1016/j.apmr.2016.08.476] [Medline: 27666157]

65. Shephard RJ. Limits to the measurement of habitual physical activity by questionnaires—commentary. Br J Sports Med 2003 Jun;37(3):197-206 [FREE Full text] [doi: 10.1136/bjsm.37.3.197] [Medline: 12782543]

66. Witt DR, Kellogg RA, Snyder MP, Dunn J. Windows into human health through wearables data analytics. Curr Opin Biomed Eng 2019 Mar;9:28-46 [FREE Full text] [doi: 10.1016/j.cobme.2019.01.001] [Medline: $\underline{31832566]}$

67. Eppeland S, Myklebust G, Hodt-Billington C, Moe-Nilssen R. Gait patterns in subjects with rheumatoid arthritis cannot be explained by reduced speed alone. Gait Posture 2009 Apr;29(3):499-503. [doi: 10.1016/j.gaitpost.2008.11.010] [Medline: 19121943]

68. Ayabe M, Aoki J, Ishii K, Takayama K, Tanaka H. Pedometer accuracy during stair climbing and bench stepping exercises. J Sports Sci Med 2008;7(2):249-254 [FREE Full text] [Medline: 24149457]

69. Huang Y, Xu J, Yu B, Shull PB. Validity of FitBit, Jawbone UP, Nike+ and other wearable devices for level and stair walking. Gait Posture 2016 Jul;48:36-41. [doi: 10.1016/j.gaitpost.2016.04.025]

70. Feito Y, Bassett DR, Thompson DL. Evaluation of activity monitors in controlled and free-living environments. Med Sci Sports Exerc 2012 Apr;44(4):733-741. [doi: 10.1249/MSS.0b013e3182351913] [Medline: 21904249]

71. Feito Y, Garner HR, Bassett DR. Evaluation of ActiGraph's low-frequency filter in laboratory and free-living environments. Med Sci Sports Exerc 2015 Jan;47(1):211-217. [doi: 10.1249/MSS.0000000000000395] [Medline: 24870583]

72. Landis JR, Koch GG. The measurement of observer agreement for categorical data. Biometrics 1977 Mar;33(1):159-174. [Medline: $\underline{843571]}$

73. Fleiss J, Levin B, Paik M. Statistical Methods for Rates and Proportions. 3rd Edition. Hoboken: Wiley-Interscience; 2003.

74. Bland JM, Altman D. Statistical methods for assessing agreement between two methods of clinical measurement. Lancet 1986 Mar 08;1(8476):307-310. [Medline: 2868172]

75. Althoff T, Sosič R, Hicks JL, King AC, Delp SL, Leskovec J. Large-scale physical activity data reveal worldwide activity inequality. Nature 2017 Jul 20;547(7663):336-339. [doi: 10.1038/nature23018] [Medline: 28693034]

76. Heath GW, Parra DC, Sarmiento OL, Andersen LB, Owen N, Goenka S, Lancet Physical Activity Series Working Group. Evidence-based intervention in physical activity: lessons from around the world. Lancet 2012 Jul 21;380(9838):272-281 [FREE Full text] [doi: 10.1016/S0140-6736(12)60816-2] [Medline: 22818939]

77. Ekelund U, Steene-Johannessen J, Brown WJ, Fagerland MW, Owen N, Powell KE, et al. Does physical activity attenuate, or even eliminate, the detrimental association of sitting time with mortality? A harmonised meta-analysis of data from more than 1 million men and women. Lancet 2016 Sep;388(10051):1302-1310. [doi: 10.1016/S0140-6736(16)30370-1] 
78. Kohl HW, Craig CL, Lambert EV, Inoue S, Alkandari JR, Leetongin G, et al. The pandemic of physical inactivity: global action for public health. Lancet 2012 Jul 21;380(9838):294-305. [doi: 10.1016/S0140-6736(12)60898-8] [Medline: 22818941]

79. Lee I, Shiroma EJ, Lobelo F, Puska P, Blair SN, Katzmarzyk PT, Lancet Physical Activity Series Working Group. Effect of physical inactivity on major non-communicable diseases worldwide: an analysis of burden of disease and life expectancy. Lancet 2012 Jul 21;380(9838):219-229 [FREE Full text] [doi: 10.1016/S0140-6736(12)61031-9] [Medline: 22818936]

80. Westerterp KR. Pattern and intensity of physical activity. Nature 2001 Mar 29;410(6828):539. [doi: 10.1038/35069142] [Medline: 11279482]

81. Global Advocacy Council for Physical Activity, International Society for Physical Activity and Health. The Toronto charter for physical activity: a global call for action. J Phys Act Health 2010 Nov; Suppl 3:S370-S385. [doi: 10.1123/jpah.7.s3.s370] [Medline: 21116016]

82. Bird EL, Baker G, Mutrie N, Ogilvie D, Sahlqvist S, Powell J. Behavior change techniques used to promote walking and cycling: a systematic review. Health Psychol 2013 Aug;32(8):829-838 [FREE Full text] [doi: 10.1037/a0032078] [Medline: 23477577]

83. Kang M, Marshall SJ, Barreira TV, Lee J. Effect of pedometer-based physical activity interventions: a meta-analysis. Res Q Exerc Sport 2009 Sep;80(3):648-655. [doi: 10.1080/02701367.2009.10599604] [Medline: 19791652]

84. Kanejima Y, Kitamura M, Izawa KP. Self-monitoring to increase physical activity in patients with cardiovascular disease: a systematic review and meta-analysis. Aging Clin Exp Res 2018 Apr 30;31(2):163-173. [doi: 10.1007/s40520-018-0960-7] [Medline: 29714027]

85. Graser S, Pangrazi R, Vincent W. Effects of placement, attachment, and weight classification on pedometer accuracy. J Phys Act Health 2007 Oct;4(4):359-369. [doi: 10.1123/jpah.4.4.359] [Medline: 18209228]

86. Sears T, Avalos E, Lawson S, Eschbach C, Bunn J. Wrist-worn physical activity trackers tend to underestimate steps during walking. Int J Exerc Sci 2017;10(5):764-773 [FREE Full text]

87. Beevi FH, Miranda J, Pedersen CF, Wagner S. An evaluation of commercial pedometers for monitoring slow walking speed populations. Telemed J E Health 2016 May;22(5):441-449. [doi: 10.1089/tmj.2015.0120] [Medline: 26451900]

88. Giannakidou DM, Kambas A, Ageloussis N, Fatouros I, Christoforidis C, Venetsanou F, et al. The validity of two Omron pedometers during treadmill walking is speed dependent. Eur J Appl Physiol 2012 Jan;112(1):49-57. [doi: 10.1007/s00421-011-1951-y] [Medline: 21479653]

89. Melanson EL, Knoll JR, Bell ML, Donahoo WT, Hill J, Nysse LJ, et al. Commercially available pedometers: considerations for accurate step counting. Prev Med 2004 Aug;39(2):361-368. [doi: 10.1016/j.ypmed.2004.01.032] [Medline: 15226047]

90. Presset B, Laurenczy B, Malatesta D, Barral J. Accuracy of a smartphone pedometer application according to different speeds and mobile phone locations in a laboratory context. J Exerc Sci Fit 2018 Aug;16(2):43-48 [FREE Full text] [doi: 10.1016/j.jesf.2018.05.001] [Medline: 30662492]

91. Washburn R, Chin MK, Montoye HJ. Accuracy of pedometer in walking and running. Res Q Exerc Sport 1980 Dec;51(4):695-702. [doi: 10.1080/02701367.1980.10609330] [Medline: 7209126]

\section{Abbreviations \\ ANOVA: analysis of variance \\ ICC: intraclass correlation coefficient \\ MAPE: mean absolute percentage error}

Edited by G Eysenbach; submitted 09.06.20; peer-reviewed by Z Svoboda, S Lim; comments to author 25.06.20; revised version
received 02.07.20; accepted 14.07.20; published 13.01.21
Please cite as:
Carlin T, Vuillerme $N$
Step and Distance Measurement From a Low-Cost Consumer-Based Hip and Wrist Activity Monitor: Protocol for a Validity and
Reliability Assessment
JMIR Res Protoc $2021 ; 10(1): e 21262$
URL: $\underline{\text { http://www.researchprotocols.org/2021/1/e21262/ }}$
doi: $\underline{10.2196 / 21262}$
PMID: $\underline{33439138}$

(CThomas Carlin, Nicolas Vuillerme. Originally published in JMIR Research Protocols (http://www.researchprotocols.org), 13.01.2021. This is an open-access article distributed under the terms of the Creative Commons Attribution License (https://creativecommons.org/licenses/by/4.0/), which permits unrestricted use, distribution, and reproduction in any medium, provided the original work, first published in JMIR Research Protocols, is properly cited. The complete bibliographic information, 
a link to the original publication on http://www.researchprotocols.org, as well as this copyright and license information must be included. 